\title{
The effect of informational faultlines configurational properties on team creativity and viability: the mediating role of information sharing
}

\author{
Xiaoqian $\mathrm{Qu}^{1}$, Cunhu $\mathrm{Xi}^{1}$ \\ ${ }^{1}$ International Business School, Shaanxi Normal University
}

\begin{abstract}
Based on team effectiveness framework and subgroup theory, this study constructs a theoretical model that aim to explore the mechanisms between informational subgroup configurations and team effectiveness. Through analyzing a sample of 64 knowledge worker teams, we obtained those following meaningful results:(1) the number of informational subgroups is positively related to open and unique of information sharing; the balance of informational subgroups is negatively related to the open information sharing while positively related to the unique information sharing. (3) The open information sharing is positively related with team viability while the unique information sharing is positively related to team creativity. Critical and insightful advice for the management of informationally diverse teams were proposed at last.
\end{abstract}

\section{Introduction}

Organizations are rarely homogeneous now. Instead, they are becoming more and more rely on informationally diverse work teams to complete complex and knowledgeintensive tasks and to achieve extraordinary effectiveness such as creativity and long run viability. Variety brings about rich and abundant cognitive resources for teams (Harrison, 2007). Nevertheless, it also increase the possibility of the formation of informational faultlines, and subsequently informational subgroups within teams (Lau \& Murnighan, 1998; Gibson \& Vermeulen, 2003). At present, research in team faultlines/subgroup domains mainly along the stream of team faultlines/subgroup strength (Lau \& Murninghan, 1998; 2005) while research concerning the configurational properties of subgroups, namely, the number and the evenness/balance of subgroups is relatively lagged behind. The configurations of subgroups were explicitly mentioned as key determinants to inter-subgroup processes and team outcomes. However, we have not developed a thorough understanding concerning the impacts of the informational subgroups configurations on critical team processes and outputs such as creativity and viability. Therefore, this research tries to answer this critical question: whether and how do informational subgroup configurational properties impact team creativity and viability?

Scholars found equal size subgroups within teams decrease satisfaction and incurs conflicts among team members (Menon and Phillips ,2011), however, O'Leary \& Motensen (2010) found that imbalance among subgroups triggers competitive and more conflicts than balance subgroup arrangements. Carton and Cummings (2012; 2013) differentiated subgroups into identity-based and knowledge-based subgroups. However, there are still important theoretical gaps need to be resolved. First, present literature concerning subgroups mainly focused on team performance (Polzer, 2006; O’Leary \& Motensen, 2010). As team creativity and viability have gradually become the critical and advanced criteria of team effectiveness, this lack of research may incur severe theoretical and practical problems. Second, the mediating mechanisms through which informational subgroup configurations act upon critical team outcomes still severely absent in present literature (Carton \& Cummings, 2013). Under the umbrella of information processing, information sharing is one of the most critical underlying mechanism between informational subgroup configurations and team creativity as well as viability.

Based on the subgroup and team effectiveness theories and adopted the information processing perspective, we proposed a theoretical model to examine whether and how the configurational properties of informational subgroups influence team creativity and viability.

\section{The effects of the number of informational subgroups on information sharing}

We conceptualized information sharing into two dimensions, that is, the open information sharing and the unique information sharing (Mesmer-Magnus \& Dechurch, 2009). We define the open information sharing as the freely and openly provision and/or receipt of the general information and feedback among team members. 
The unique information sharing is defined as the sharing of unique, uncommon and distinct task-related knowledge, information and perspectives among team members. These two dimensions of information sharing are orthogonal related.

Because of the inherent distinct nature of open and unique information sharing, the number of subgroups impact these two types of information sharing through distinct mechanisms. When two subgroups exists within teams, this dichotomous categorization "primes the competition orientation" and activate inter-subgroup discrimination, which easily incur conflicts, competition and even interpersonal hostility between distinct informational subgroup members (Earley \& Mosakowski, 2000), make them reluctant to actively and openly share critical development and progress information with members from opposing subgroups and hesitate to keep them "in the loop" during task. However, the presence of a third or fourth informational subgroups lower the salience of inter-subgroup comparisons and subsequently competition atmosphere among subgroups, which means that the inter-subgroup bias is less evident when team exists more than two subgroups. Hypothesis 1a (H1a): The number of informational subgroups is positively related with open information sharing.

We claimed that as the number of informational subgroups grows, more unique and distinct sets of information will be exchanged and shared among team members. First, the formation of informational subgroups are based on variety (Harrison \& Klein, 2007), which means that each subgroup can provide different and unique knowledge, skills, information for teams to discuss and more alternatives for teams to elaborate on. Therefore, more informational subgroups formed and emerged within teams, more unique and task-relevant knowledge, information, perspectives and insights can be shared within teams. Additionally, the formation of informational subgroups can inhibit the detrimental effect of "hidden profile" information sampling bias in teams, which implies that team members are more likely to discuss and elaborate on the shared rather than unshared information in decision making.

Hypothesis $1 \mathrm{~b}(\mathrm{H} 1 \mathrm{~b})$ : Among teams with two or more informational subgroups, the number of informational subgroups is positively related with unique information sharing.

\section{The effects of the balance of informational subgroups on information sharing}

As informational subgroups becoming more equallyarranged, the power will be gradually equally distributed across subgroups, so that team members are more likely to take other subgroups as emerging threatens to their distinctive identities, which will incur negative affective and evaluation tendency toward dissimilar others and even severe status conflicts (Spoelma \& Ellis, 2017). Particularly, when teams containing two equal-sized informational subgroups, the distinction and boundary between subgroups are most clear, negative intersubgroup bias will inhibit the capability of different subgroups to work together (Philip et al, 2004). Therefore, team members will be hesitate to proactively inform dissimilar others and to keep the team members from other informational subgroups "in the loop". Even in teams existing more than two subgroups, equal-sized arrangements of subgroups still make each subgroups confronted with the threatens from other subgroups, the clear distinctions of subgroup identities will incur the social categorization process, which will resulted in the unwillingness of members to show kindness and prosocial behaviors to inform distinct subgroups members the latest information regarding the development and progress in tasks.

Hypothesis 2a (H2a): Among teams with two or more informational subgroups, the balance of informational subgroups is negatively related with the open information sharing.

Even though scholars argue that the formation of informational subgroups and the inter-subgroup dynamics are based on the information processing perspective, according to the social dominance theory, variation of the size of subgroups will resulted in that the discussion and decision-making processes lead and dominated by relatively large-size subgroups because that larger subgroups have more social power and internal support. At the same time, unique information and dissent that brought out by the numerical minorities could be suppressed and marginalized within teams because they have smaller voice power (Carton \& Cummings, 2012). In the long run, the intentions to share unique information and knowledge of minorities will be smothered and withheld because of the disadvantage of numerical minority. However, when equal-sized informational subgroups are formed, this configuration make each subgroup well-represented within teams. Therefore, each subgroup has the equal voice/chance to express their uncommon and unique perspectives and share their distinct expertise and information without the fear of being criticized by numerical majorities, allowing the sharing of unique information and viewpoints among different informational subgroups to happen.

Hypothesis 2b (H2b): The balance of information subgroups is positively related with the unique information sharing.

\section{Information sharing, team creativity and team viability}

Making statements to other group members about the present task and keep other subgroups "in the loop" through informal communication are typical phenomenon of the open information sharing, which indicate a cohesive, mutual trust and psychological safety climate formed among team members, regardless of the functional and educational background. Each member feels respected and valued, everyone build a positive relationship with others 
and the working climate is pleasant and team members are satisfied. This will increase the willingness of members to retain their membership, working together with other members and the chance of prosperity of teams will be increased in the long run (Bell \& Marentette, 2007).

Furthermore, as team members try their best to keep one another up to date on their activities, the mutual trust and psychological safety will lead to a risk-taking climate, which afford the team members with emotional and social support to resolve present problems and change the inefficient procedure and processes that widely used in teams in a creative way. Furthermore, the openly and freely sharing of information also increases the belongingness of team members and then the team identification, which makes team members contribute all of their knowledge, information and perspectives to the team as a whole, and the combination and recombination of knowledge from multiple domains are more likely to happen.

Hypothesis $3 \mathrm{a}(\mathrm{H} 3 \mathrm{a})$ : the open information sharing is positively related with team viability.

Hypothesis $3 b(\mathrm{H} 3 b)$ : the open information sharing is positively related with team creativity.

Putting forward unique, unshared and uncommon taskrelated information easily incurs dissent, disputes conflicts among team members, especially in teams containing several subgroups. The inter-subgroup bias maybe activated during discussion when each team member express their own unique and even opposing viewpoints because the distinction is clear. Therefore, sharing unique information in teams where subgroups exists inhibit the formation of a supportive, safe and respective climate and even create fracture within teams. These consequences will lead to the increased willingness of members to leaving this team and disentangle their team membership because the lower ego, severe task conflicts and unsafe experience during the team interaction process.

The meta-analysis results demonstrated that internal communication and information sharing was critical predictor for team creativity (Hulsheger \& Anderson, 2009). The exchange of unshared and unique information from different knowledge and functional domains can impetus the cross-fertilization of ideas and the new way to rethink and recombine the existing knowledge, which will increase the generation of non-routine and unusual problem solving approaches.

Hypothesis 5a (H5a): the unique information sharing is negatively related with team viability.

Hypothesis $5 \mathrm{~b}(\mathrm{H} 5 \mathrm{~b})$ : the unique information sharing is positively related with team creativity.

The theoretical model are presented in figure 1.

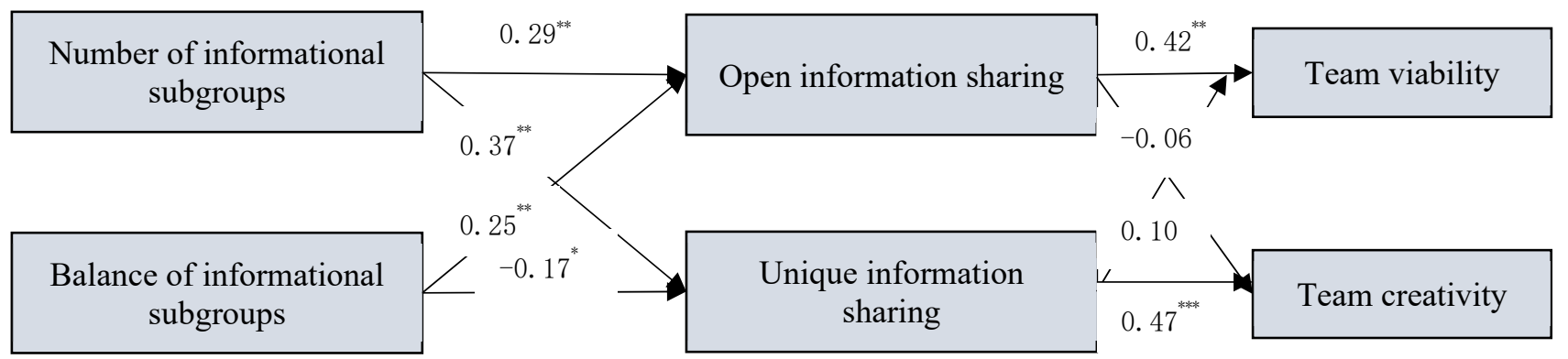

Fig 1. Theoretical model and Structural equation model results

Note. $\mathrm{N}=64 .{ }^{*} \mathrm{p}<.05 .{ }^{*} \mathrm{p}<.01 . * * * \mathrm{p}<.001$. Standardized coefficient are reported. Control variables are not shown for ease of presentation.

\section{Method}

\subsection{Sample and data collection}

The data used in the present study was collected from 64 knowledge worker teams in seven firms in ShaanXi and HeNan provinces of China. Team members reported on the individual characteristics, the uniqueness and open information sharing, team viability, and task complexity. Direct supervisors reported their team's basic level of information and evaluated team creativity. In the final sample we chose teams with within-team response rates higher than $80 \%$, which has been found to be acceptable in team composition studies (Carton \& Cummings, 2013; Shin \& Zhou, 2007).

\subsection{Measurement}

Informational subgroup configurational properties. We used the ASW (average silhouette width) method to calculate the configurational properties of informational faultlines. The balance of subgroups can be obtained by the standard deviation of the size of the given subgroups, multiplied by -1 . The number of informational subgroups can be directly obtained from ASW, which ranged from 2 to 4 in the current study. Informational faultlines strength ranged from 0.352 to 0.911 in the research.

Information sharing. Typical item was "team members 
effectively share specialized information and knowledge during discussion". We used the scale that Bunderson and Sutcliff (2002) developed to assess the open information sharing.

Team creativity. We adopted the scale that invented by Shin and Zhou (2007) to measure knowledge worker team creativity. Typical items was "How well does your team produce new ideas?" Cronbach $\alpha=0.92$.

Team viability. We adopted the 12-item scale that Barrick and colleagues invented (1998) to measure team viability. Typical items was "I believe that my personal well-being has been improved as a result of participating in this team". Cronbach $\alpha=0.88$.

Control variables. We controlled for team size, team tenure, and task complexity in the present research to eliminate the possible effects of these variables on the relationship among informational subgroup configurations, information sharing, team creativity and viability (Mesmer-Magnus \& DeChurch, 2009; Ellis et al., 2013; Thatcher \& Patel, 2011). We also controlled for informational faultlines strength to obtain the unique effect of informational subgroups configurational properties on information sharing and team effectiveness

\section{Aggregation}

The theoretical and empirical analysis of the current study was set at the team level. For information sharing, team viability and task complexity, we calculated three statistical indexes to justify the aggregation of the individual-level data up to the team level: $r_{w g}$, ICC1 and ICC2 . These indices empirically justified the aggregation of individual-level data to the team level.

\subsection{Confirmative factor analysis (CFA) and correlations}

We used Mplus 8.2 to conduct CFA. Results showed that the factor loadings of all the latent variables exceeded the cutoff value of 0.6 , this indicated the convergent validity of all latent variables were verified. By calculating the square root value of AVE, we could determine the discriminant validity of scales by checking whether this value was larger than the absolute value of the correlations of the focal variable with any other variables.

\begin{tabular}{|c|c|c|c|c|c|c|c|c|c|c|c|}
\hline variable & M & SD & 1 & 2 & 3 & 4 & 5 & 6 & 7 & 8 & 0 \\
\hline 1 team tenure & 1.76 & 0.82 & & & & & & & & & \\
\hline 2 team size & 742 & 324 & 000 & & & & & & & & \\
\hline 3 leader sex & 060 & 015 & 003 & 0 & & & & & & & \\
\hline & 0.09 & 0.15 & -0.05 & 0.00 & & & & & & & \\
\hline 4leader tenure & 6.79 & 4.56 & 0.15 & 0.01 & 0.00 & & & & & & \\
\hline 5 idea generation & 5.01 & 0.68 & $-0.09^{*}$ & 0.03 & 0.07 & -0.03 & & & & & \\
\hline $\begin{array}{l}6 \text { idea } \\
\text { implementation }\end{array}$ & 4.78 & 0.53 & 0.05 & 0.08 & -0.06 & $0.12^{*}$ & 0.07 & & & & \\
\hline $\begin{array}{l}\text { 7leader performance- } \\
\text { prove goal } \\
\text { orientation }\end{array}$ & 5.23 & 0.79 & 0.01 & -0.02 & $0.13^{*}$ & -0.01 & $0 . .01$ & $0.37^{* * *}$ & & & \\
\hline $\begin{array}{l}8 \text { leader } \\
\text { ambassadorial } \\
\text { activity }\end{array}$ & 4.98 & 0.74 & 0.02 & -0.03 & $0.11^{*}$ & -0.03 & $0.27^{* *}$ & $0.42^{* * *}$ & $0.34^{* * * *}$ & & \\
\hline $\begin{array}{l}9 \text { leader task } \\
\text { coordination activity }\end{array}$ & 5.12 & 0.67 & -0.03 & -0.03 & $0.09^{*}$ & -0.05 & $0.29^{* *}$ & $0.19^{*}$ & $0.21^{*}$ & $0.15^{*}$ & \\
\hline
\end{tabular}

Note $: \mathrm{N}=83 ;{ }^{*} \mathrm{p}<0.05 ;{ }^{* *} \mathrm{p}<0.01 ; * * \mathrm{p}<0.001$

\subsection{Hypotheses testing}

We conducted team-level SEM to test hypotheses (Chen, Mathieu, \& Bliese, 2004). All the results were summarized in figure 1. This SEM demonstrated indices to test the model fit to the data, and indices showed a satisfactory model fit: $x 2 / \mathrm{df}=1.04, \mathrm{p}<0.000, \quad \mathrm{CFI}=0.95$, RMSEA $=0.03$, and $\mathrm{SRMR}=0.07$.

As demonstrated in Figure 1, the number of informational subgroups is positively related to the open information sharing $(\beta=.29, \mathrm{p}<0.01)$ and the unique information sharing $(\beta=.37, \mathrm{p}<0.01)$, therefore H1a and $\mathrm{H} 1 \mathrm{~b}$ were supported. $\mathrm{H} 2 \mathrm{a}$ and $\mathrm{H} 2 \mathrm{~b}$ proposed that among teams with two or more informational subgroups, the balance of informational subgroups is negatively related with the open information sharing while positively related with the unique information sharing. From figure 1 we can see that the estimated standardized path coefficient from the evenness of informational subgroups to the open information sharing is significantly negative $(\beta=-.17, \mathrm{p}<$ $0.05)$, therefore, H2a was supported. Figure 1 also showed that the estimated path coefficient from the balance of informational subgroups to the unique information sharing is positive and significant, $\beta=.35, p<0.01$, this finding indicates $\mathrm{H} 2 \mathrm{~b}$ was supported in the present research. As illustrated in figure 1, open information sharing is positively related to team viability $(\beta=.42, \mathrm{p}<0.001)$ while not significantly related with team creativity $(\beta=-.06$, $\mathrm{p}>0.05)$. Therefore, $\mathrm{H} 3 \mathrm{a}$ was supported while and $\mathrm{H} 3 \mathrm{~b}$ was not. Finally, from figure 1 we can see that unique information sharing is not significantly related to team viability $(\beta=-.10, p>0.05)$ while positively related to team creativity $(\beta=.47, \mathrm{p}<0.001)$. Therefore, H4a was not supported while H4b was supported.

\section{Discussion}

First, the number informational subgroups is positively 
related to the uniqueness and open information sharing. The balance of informational subgroups is positively related to the unique information sharing while negatively related to the open information sharing. Second, we found the unique information sharing enhance team creativity rather than team viability while the open information sharing activates team viability rather than team creativity. The direct effects of the open and unique information sharing on team creativity and team viability respectively were not supported in our research.

\subsection{Theoretical implications}

First, our study advances subgroup literature to a large extent by exploring the relationship between informational subgroups configurations and team creativity as well as viability in-depth. The unique effects of configurations of informational subgroups above and beyond informational faultlines strength on team viability and creativity were found in the current research, echoes to the call for more attention and research concerning the effects of the configurational properties of subgroups. Additionally, we are one of the first that examine the antecedent factors for team creativity and team viability from the perspective of informational subgroup configurations, which significantly extends research on team creativity as well as viability. Second, our study is among the first to examine the underlying function of information sharing between informational subgroups configurations and team creativity as well as viability from the perspective of information processing (Carton \& Cummings, 2007). Third, our results partly explains the inconsistent results regarding the impact of information sharing on team effectiveness (Mesmer-Magnus and DeChurch, 2009), verifying the theoretical rationale of the two-dimensional typology of team information sharing and providing critical empirical foundation for future research.

\subsection{Managerial implications}

According to these empirical results, we suggest that teams should pay attention to the configurational properties of informational subgroups when different team effectiveness criteria was desired and pursued. Second, our study demonstrates that team members' willingness to proactively share information can enhance the social and emotional attachment/ties within teams. Therefore, team leaders should through building role models and language persuasive to enhance the freely and openly sharing of information among team members that have distinct education and function background.

\section{References}

1. Bunderson, J. S., \& Sutcliffe, K. M. (2002). Comparing alternative conceptualizations of functional diversity in management teams: Process and performance effects. Academy of Management
Journal, 45, 875-893.

2. Carton, A. M., \& Cummings, J. N. (2013). The impact of subgroup type and subgroup configurational properties on work team performance. Journal of Applied Psychology, 98(5), 732-758.

3. Cooper, D., Patel, P. C., \& Thatcher, S. M. B. (2014). It depends: Environmental context and the effects of faultlines on top management team performance. Organization Science, 633-652.

4. Chen, G., Mathieu, J. E., \& Bliese, P. D. (2004). A framework for conducting multi-level construct validation. Research in Multi-Level Issues, 3, 273303.

5. Earley, C. P., \& Mosakowski, E. (2000). Creating hybrid team cultures: An empirical test of transnational team functioning. Academy of Management journal, 43(1), 26-49.

6. Harrison, D. A., \& Klein, K. J. (2007). What's the Difference? Diversity Constructs as Separation, Variety, or Disparity in Organizations. Academy of Management Review, 32(4), 1199-1228.

7. Hartstone, M., \& Augoustinos, M.. (1995). The minimal group paradigm: categorization into two versus three groups. European Journal of Social Psychology, 25(2), 179-193.

8. Hinsz, V. B., Tindale, R. S., \& Vollrath, D. A. (1997). The emerging conceptualization of groups as information processors. Psychology Bulletin, 121(1), 43-64.

9. Lau, D. C., \& Murnighan, J. K. (1998). Demographic diversity and faultlines: The compositional dynamics of organizational groups. Academy of Management Review, 23(2), 325-340.

10. Mesmer-Magnus, J. R., \& DeChurch, L. A. (2009). Information sharing and team performance: A metaanalysis. Journal of Applied Psychology, 94(2), 535546.

11. O'Leary, M. B., \& Mortensen, M. (2010). Go (Con)figure: Subgroups, imbalance, and isolates in geographically dispersed teams. Organization Science, 21(1), 115-131.

12. Polzer, J. T., Crisp, C. B., Jarvenpaa, S. L., \& Kim, J. W. (2006). Extending the faultline model to geographically dispersed teams: How colocated subgroups can impair group functioning. Academy of Management Journal, 49(4), 679-692.

13. Shin, S. J., \& Zhou, J. (2007). When is educational specialization heterogeneity related to creativity in research and development teams? Transformational leadership as a moderator. Journal of Applied Psychology, 92(6), 1709-1721. 